\title{
Counting the lives saved by DOTS in India: a model-based approach
}

Sandip Mandal ${ }^{1 *}$, Vineet K. Chadha², Ramanan Laxminarayan ${ }^{1,3,4}$ and Nimalan Arinaminpathy ${ }^{1,5}$

\begin{abstract}
Background: Against the backdrop of renewed efforts to control tuberculosis (TB) worldwide, there is a need for improved methods to estimate the public health impact of TB programmes. Such methods should not only address the improved outcomes amongst those receiving care but should also account for the impact of TB services on reducing transmission.

Methods: Vital registration data in India are not sufficiently reliable for estimates of TB mortality. As an alternative approach, we developed a mathematical model of TB transmission dynamics and mortality, capturing the scale-up of DOTS in India, through the rollout of the Revised National TB Control Programme (RNTCP). We used available data from the literature to calculate TB mortality hazards amongst untreated TB; amongst cases treated under RNTCP; and amongst cases treated under non-RNTCP conditions. Using a Bayesian evidence synthesis framework, we combined these data with current estimates for the TB burden in India to calibrate the transmission model. We simulated the national TB epidemic in the presence and absence of the DOTS programme, measuring lives saved as the difference in TB deaths between these scenarios.
\end{abstract}

Results: From 1997 to 2016, India's RNTCP has saved 7.75 million lives (95\% Bayesian credible interval 6.29-8.82 million). We estimate that $42 \%$ of this impact was due to the 'indirect' effects of the RNTCP in averting transmission as well as improving treatment outcomes.

Conclusions: When expanding high-quality TB services, a substantial proportion of overall impact derives from preventive, as well as curative, benefits. Mathematical models, together with sufficient data, can be a helpful tool in estimating the true population impact of major disease control programmes.

Keywords: India, Tuberculosis, Modelling, Deaths averted

\section{Background}

India is the highest tuberculosis (TB)-burdened country in the world, accounting for about a quarter of all incident cases and TB deaths [1]. Following a review of the erstwhile National TB Programme (NTP) in 1992, the Government of India decided to implement the Revised National TB Control Programme (RNTCP), adopting the internationally recommended Directly Observed Treatment, Short Course (DOTS) strategy [2] based on five principles: political and administrative commitment; good-quality diagnosis; uninterrupted supply of quality drugs; directly observed treatment (DOT); and systematic

* Correspondence: sandip.mandal@phfi.org

${ }^{1}$ Public Health Foundation of India, New Delhi, India

Full list of author information is available at the end of the article monitoring and accountability. Following a pilot from 1993 to 1996, the RNTCP was formally launched in 1997 and expanded in a phased manner to all the districts in the country by 2006 [3].

While DOTS remains a mainstay of TB control today, recent years have seen a shift in the ways in which DOTS programmes, such as RNTCP, are evaluated. For example, a major goal for RNTCP was to meet the primary targets of case detection of at least $70 \%$ of smearpositive incident TB cases and a cure rate of at least $85 \%$ in these cases. The TB-related Millennium Development Goals (MDGs) and the WHO's Stop TB Strategy emphasized impact as well as programmatic implementation [4-6]: they posed targets of halving TB mortality and prevalence by 2015 , compared to 1990 , and reversing 
trends in TB incidence. More recently, the End TB strategy calls for concerted action to reduce $\mathrm{TB}$ deaths by 95\% between 2015 and 2035 [7].

There is therefore increasing emphasis on how many TB deaths are averted ('lives saved') by improving TB services. The main approach to this question has been to multiply the number of patients treated under RNTCP by the percentage reduction in case fatality rates under RNTCP compared to the erstwhile NTP $[8,9]$. While straightforward and transparent, a limitation of this approach is that it does not account for 'indirect' effects, that is, the fact that effective treatment reduces opportunities for transmission by shortening a patient's infectious period. Lives are thus saved by averting transmission as well as by improving treatment outcomes [10, 11].

A strong vital registration system is the most direct approach for estimating lives saved. However, India's vital registration system captures less than half of the total deaths: it has several challenges, including poorer coverage in earlier years, non-reliability of data on underlying cause of death (COD) and a high proportion of garbage coding [12-14]. These issues preclude direct measurement of TB-specific mortality rates.

Mathematical modelling offers an alternative approach, providing a systematic framework for capturing the dynamics of TB transmission and enabling estimates of program impact. Combined with Bayesian evidence synthesis methods, such models can incorporate evidence and uncertainty from a range of disparate sources, including mortality rates and epidemiological and programmatic data $[15,16]$.

Previous analyses by RNTCP estimated that the programme averted 1.26 million deaths from 1997 to 2006 [17], using a method similar to that described above: comparing mortality rates amongst those treated within the programme with those treated in the erstwhile NTP, which was operational since 1962 (as described, for example, in [10]). In the present work we incorporate transmission using mathematical modelling. In what follows, we give a brief overview of some essential features of RNTCP and the Indian healthcare system that are relevant to the current analysis. We then describe the model framework, the different data sources involved and the Bayesian synthesis framework. We present results for projected epidemics on a national scale, in the presence and absence of RNTCP. We show implications for the lives saved by RNTCP. Finally, we discuss implications of this work: the limitations of the model, relevance for other national settings and questions arising for future work.

\section{Methods}

\section{Overview of RNTCP services}

India's RNTCP is the world's largest national TB programme in terms of numbers of patients on $\mathrm{TB}$ treatment. When it was launched in 1997 to replace the erstwhile National Tuberculosis Programme (NTP), its purpose was to reform and coordinate $\mathrm{TB}$ services on a national level, in line with DOTS standards of TB care. In particular, improved standards of $\mathrm{TB}$ treatment involved enhanced adherence support amongst patients taking treatment; strengthened patient monitoring; and the use of a standard treatment regimen [2]. In turn, regarding new $\mathrm{TB}$ cases, in India this regimen involved four fully supervised first-line drugs (isoniazid $(\mathrm{H})$, rifampicin (R), pyrazinamide (Z) and ethambutol (E)) given thrice a week for 8 weeks, followed by two partially supervised drugs $(H, R)$ for 16 weeks. Further, to address the threat of multi-drug-resistant TB (MDR-TB), Programmatic Management of Drug-Resistant TB (PMDT) was subsequently introduced in 2007. These cases are treated with daily dosages of six drugs including second-line drugs for a minimum of 24 weeks followed by four drugs for 18 months, fully supervised over the full course of treatment.

Overall, these services had not been available in a nationally coordinated way under the erstwhile NTP and, by addressing these shortfalls, RNTCP aimed to maximize adherence and cure rates amongst patients on TB treatment. Here, we refer to these improvements collectively as 'RNTCP services'.

However, another major feature in the Indian healthcare system is the private sector, where a substantial proportion of TB patients receive care. Vast, fragmented and unregulated, this sector provides TB care that is often substandard [18-22]. Available evidence suggests, firstly, that before RNTCP scale-up, the erstwhile NTP and the private sector had comparable standards of TB care [23, 24], and secondly, that there have not been significant improvements in the private sector since that time $[20,25]$. In the present work, we therefore only distinguish RNTCP vs non-RNTCP services, taking the latter to combine both the erstwhile NTP and the private healthcare sector. We estimate lives saved by RNTCP services by comparing TB mortality against a counterfactual where TB care simply continued at the standard of the NTP and the private sector ('non-RNTCP'), projected forward without change.

\section{The modelling framework}

We developed a deterministic, compartmental mathematical model to capture the essential dynamics of diagnosis, treatment and transmission of TB in India, including the scale-up of RNTCP services. Key transmission and delay parameters in the model were calibrated by fitting the model to WHO estimates of incidence and prevalence in India (Table 1) [1]. Further, we used values from the literature for mortality hazards amongst cases undergoing treatment in RNTCP and amongst cases undergoing 
Table 1 Calibration targets for the model. Estimates for incidence and proportion MDR are taken from the Global TB Report 2016, while prevalence estimates are taken from a recent pooled analysis of prevalence surveys in India, reported in [27]

\begin{tabular}{ll}
\hline Indicator & Calibration target \\
\hline Incidence in 2015 & $\begin{array}{l}217(112-355) \text { per 100,000 } \\
\text { population }\end{array}$ \\
& $\begin{array}{l}253(195-312) \text { per 100,000 } \\
\text { population }\end{array}$ \\
Prevalence in 2015 & $\begin{array}{l}3.1 \%(2.6-3.7) \text { (averaged over new } \\
\text { and retreatment cases) }\end{array}$ \\
Proportion MDR & $\begin{array}{l}19.61 \text { million (17.65-21.57 million) } \\
\text { (allowing for 10\% error) }\end{array}$ \\
$\begin{array}{l}\text { Cumulative notifications to public } \\
\text { sector (1997-2015) }\end{array}$ & $\begin{array}{l}92,753 \text { (83,478-102,028) (allowing } \\
\text { for 10\% error) }\end{array}$ \\
notifications (2007-2015) &
\end{tabular}

treatment elsewhere. Mortality hazards for untreated cases were obtained from studies identified in a systematic review on the natural history of untreated TB [26]. Incorporating these hazards in the transmission model, we estimated the lives saved by RNTCP between 1997 and 2016. To estimate uncertainty intervals, we embedded this process in a Bayesian framework to systematically capture contributions from uncertainty in the model inputs (mortality hazards and other parameters) as well as in the calibration targets (incidence and prevalence [27]). Further details of these components are given below.

\section{Transmission model structure}

Figure 1 illustrates the compartmental model structure. For simplicity, the model ignores distinctions between different forms of $\mathrm{TB}$, for example, smear-positive/ smear-negative/extrapulmonary $\mathrm{TB}$ or adult/pediatric TB. Instead, the model assumes a rate of infection (parameter $\beta$, to be estimated) that is essentially averaged over these different forms of TB. With less than $5 \%$ of TB cases in India being HIV-coinfected [1], we ignore the role of HIV in these dynamics.

The rate $r$ (to be estimated) reflects the delay from the start of symptoms to the initiation of $\mathrm{TB}$ treatment under RNTCP or elsewhere: accordingly, it reflects the sum of the initial patient delay before care seeking, along with the subsequent delay before diagnosis and initiation of treatment, during which a patient may visit several different providers. The model distinguishes types of providers only at the point of treatment initiation, assuming that a proportion $p$ of first-line treatment initiations are in RNTCP (the ' $\mathrm{T}_{\text {RNTCP }}$ ' compartment), and

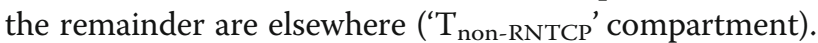
As described below, we chose the time evolution of $p$ to capture RNTCP scale-up. Here, the differences between RNTCP and non-RNTCP services are: (1) higher rates of treatment completion and success under RNTCP; (2) lower mortality while on treatment; (3) a lower risk of acquisition of MDR-TB from first-line treatment under RNTCP; (4) the availability of standard second-line treatment in RNTCP. For a given parameter set, we initialized the model by simulating the TB epidemic to equilibrium, in the absence of RNTCP. We then projected the model forward in time from 1997 to 2016, incorporating RNTCP scale-up from 1997 to 2007 and allowing for an annual 1.2\% increase in total population size from 1997 onwards. We then assessed the model fits to the calibration data as of 2016, as described below.

Flows between compartments, including the infection process, were captured by a system of differential equations. Model parameters are listed in Table 2. Further technical details, including the governing equations, are given in Additional file 1.

\section{Capturing scale-up of RNTCP services}

For the proportion of cases $p(t)$ receiving first-line treatment through RNTCP at a given time $t$, we used programme data for RNTCP geographical coverage (Fig. 2, blue points) as a proxy for scale-up, modelled using a logistic function (Fig. 2, blue curve; see figure legend for associated coefficients). In the model, the parameter $p_{\max }$ (the ultimate 'plateau' for $p(t)$ ) was subsequently chosen to give the correct, cumulative notifications (public-sector treatment initiations) up to 2015.

Similarly, for coordinated MDR-TB services (PMDT), as a proxy for scale-up we used data for the numbers of MDR-TB cases notified to the programme (Fig. 2, red points). The red curve $G(t)$ illustrates the logistic function used to model the pace of PMDT scale-up, with coefficients again given in the legend. In the model we took $q(t)=q_{\max } G(t)$, where the parameter $q_{\max }$ was chosen to give the correct cumulative number of notifications of MDR-TB up to 2015.

\section{Epidemiological data}

We calibrated the model to TB incidence and prevalence. WHO estimates for TB incidence have recently been revised upwards substantially, in light of growing evidence that the true TB burden in India is greater than was previously recognized [1]. We used the updated, 2015 estimates for incidence. However, in the absence of similarly updated prevalence estimates, we drew instead from a recent analysis pooling subnational prevalence surveys at different sites in India and reported in [27], taking this estimate to represent national TB prevalence in 2015. While information on trends would be helpful, the most recent WHO estimates in incidence trends are based on further assumptions, namely that trends for incidence mirror those in the Annual Risk of TB Infection (ARTI) $[1,28]$. Therefore, to avoid fitting our model to what is essentially another model, we limited the calibration only to the single time points described above, 


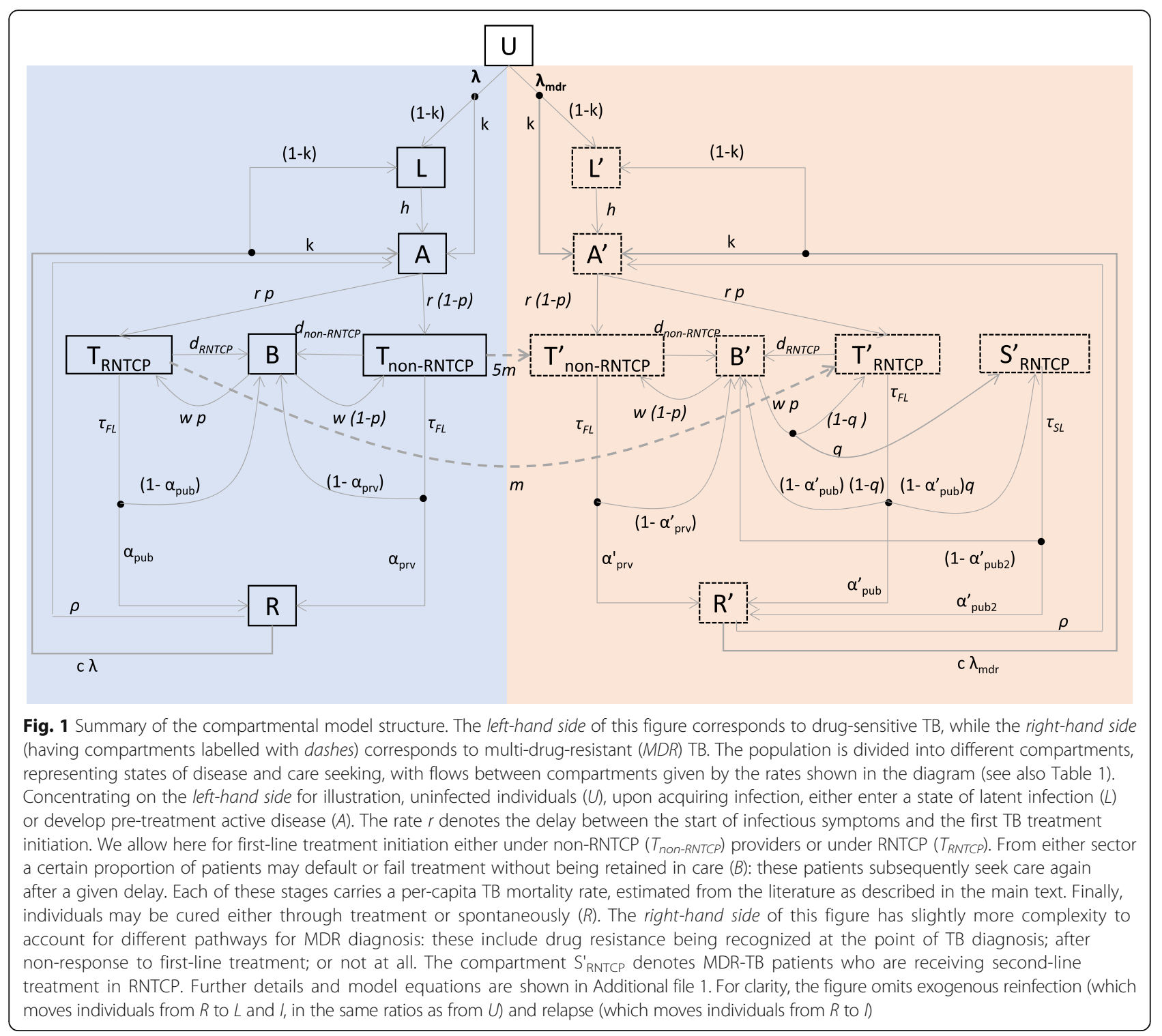

leaving it to the uncertainty estimation to capture the different trends that would meet these targets. We modelled these incidence and prevalence estimates and their accompanying $95 \%$ uncertainty intervals, using lognormal probability distributions, to incorporate these distributions in the Bayesian melding procedure described below.

\section{Mortality hazards}

Owing to challenges with vital registration data $[9,12]$, we drew from the literature for different mortality hazards in the model. In particular, we populated four different types of mortality: amongst untreated TB $\left(\mu_{\mathrm{UTB}}\right)$, amongst those receiving treatment in RNTCP $\left(\mu_{\mathrm{RNTCP}}\right)$; amongst those receiving treatment outside RNTCP $\left(\mu_{\text {non-RNTCP }}\right)$; and amongst those who have undergone failure or default $\left(\mu_{\mathrm{B}}\right)$.
For data on $\mu_{\mathrm{UTB}}$, sources were drawn from a systematic review [26]. We analysed the survival data from these studies to estimate the overall hazard of mortality, allowing for variation between studies using exponential regression with random effects. For $\mu_{\mathrm{RNTCB}}$ as discussed in the Additional file 1, we drew from programmatic data, constructing uncertainty to capture the annual variability in these data. There was less information on $\mu_{\text {non-RNTCP }}$ and $\mu_{\mathrm{B}}$, each informed by only one source in the peer-reviewed literature $[29,30]$. Accordingly, we adopted estimates from these respective sources, while allowing for broad uncertainty around these estimates.

\section{Estimating lives saved}

For a given set of model parameters, we simulated the numbers of $\mathrm{TB}$ deaths in the presence and absence of 
Table 2 Parameter values used and estimated in the model. Numbers in brackets show the uncertainty ranges used in the simulations (for input parameters) or Bayesian credible intervals (for parameters being estimated)

\begin{tabular}{|c|c|c|c|}
\hline Parameter name & Symbol & Value & Note/source \\
\hline $\begin{array}{l}\text { Average number of infections per } \\
\text { drug-susceptible (DS) TB case per year }\end{array}$ & $\beta$ & $10.7[5.8-13.6]$ & Estimated \\
\hline $\begin{array}{l}\text { Average number of infections } \\
\text { per MDR-TB case per year }\end{array}$ & $\beta_{m d r}$ & $2.00[1.62-2.62]$ & Estimated \\
\hline $\begin{array}{l}\text { Per care seeking attempt, probability of } \\
\text { seeking care in the public sector } \\
\text { (following RNTCP scale-up) }\end{array}$ & $p_{\max }$ & $0.34[0.25-0.58]$ & $\begin{array}{l}\text { Estimated to get reported } \\
\text { notifications from 1997-2015 }\end{array}$ \\
\hline $\begin{array}{l}\text { Proportion of MDR-TB cases whose drug } \\
\text { resistance is recognized at the point of TB } \\
\text { diagnosis and who start appropriate treatment }\end{array}$ & $q_{\max }$ & $0.07[0.06-0.09]$ & $\begin{array}{l}\text { Estimated to get reported } \\
\text { notifications from 2007-2015 }\end{array}$ \\
\hline $\begin{array}{l}\text { Reduction in force of infection owing } \\
\text { to previous infection }\end{array}$ & C & 0.5 & Assumed \\
\hline $\begin{array}{l}\text { Proportion of infections undergoing } \\
\text { 'rapid' progression }\end{array}$ & k & 0.15 & Vynnycky and Fine, 1997 [42] \\
\hline $\begin{array}{l}\text { Rate of breakdown from remote } \\
\text { infection to active disease }\end{array}$ & $h$ & $0.001 y^{-1}$ & Horsburgh et al., 2010 [43] \\
\hline $\begin{array}{l}\text { Rate corresponding to the delay from the } \\
\text { start of symptoms to the initiation of treatment } \\
\text { (whether in public or private sector) }\end{array}$ & r & $3.29 y^{-1}[0.83-5.70]$ & Estimated \\
\hline Mean duration of first-line treatment & $\tau_{F L}$ & $2 y^{-1}$ & $\begin{array}{l}\text { Corresponding to } 6 \text { months of } \\
\text { treatment duration }\end{array}$ \\
\hline Rate of default from non-RNTCP treatment & $d_{\text {RNTCP }}$ & $1.06 y^{-1}$ & Uplekar et al. 1998 [29] \\
\hline Rate of default from RNTCP treatment & $d_{\text {non-RNTCP }}$ & $0.049 y^{-1}$ & $\begin{array}{l}\text { Corresponds to } 4.8 \% \text { default in } \\
\text { RNTCP (TB India, } 2015 \text { [34]) (averaged } \\
\text { over smear-positive, smear-negative } \\
\text { and extrapulmonary TB) }\end{array}$ \\
\hline $\begin{array}{l}\text { Rate of repeat care seeking after } \\
\text { recurrence or failure }\end{array}$ & w & $4 y^{-1}$ & $\begin{array}{l}\text { Corresponds to } 3 \text { months of } \\
\text { delay period }\end{array}$ \\
\hline Annual recurrence rate & $\rho$ & $0.003 y^{-1}$ & $\begin{array}{l}\text { Corresponds to lifetime recurrence } \\
\text { risk of } 17 \% \text { (Sun et al., } 2013 \text { [44]) }\end{array}$ \\
\hline $\begin{array}{l}\text { Rate of primary MDR acquisition from } \\
\text { patient treated under RNTCP }\end{array}$ & $m$ & $0.02 y^{-1}$ & TB India, 2015 [34] \\
\hline Mean duration of second-line treatment & $T_{S L}$ & $0.5 y^{-1}$ & $\begin{array}{l}\text { Corresponding to } 2 \text { years of } \\
\text { treatment duration }\end{array}$ \\
\hline Spontaneous cure rate & $\sigma$ & $0.166 y^{-1}$ & $\begin{array}{l}\text { Corresponds to 50\% spontaneous } \\
\text { cure in } 3 \text { years alongside with } \\
\text { TB mortality (Tiemersma et al., } 2011 \text { [26]) }\end{array}$ \\
\hline $\begin{array}{l}\text { Proportion cure of drug-susceptible } \\
\text { (DS)-TB in RNTCP after first-line treatment }\end{array}$ & $a_{\text {pub }}$ & 0.87 & TB India, 2015 [34] \\
\hline $\begin{array}{l}\text { Proportion cure of DS-TB in non-RNTCP } \\
\text { after first-line treatment }\end{array}$ & $a_{p r v}$ & 0.51 & Uplekar et al., 1998 [29] \\
\hline $\begin{array}{l}\text { Proportion cure of MDR-TB in RNTCP } \\
\text { after first-line treatment (excluding self-cure) }\end{array}$ & $a_{\text {pub }}^{\prime}$ & 0.24 & TB India, 2015 [34] \\
\hline $\begin{array}{l}\text { Proportion cure of MDR-TB in } \\
\text { non-RNTCP after first-line treatment }\end{array}$ & $a_{p r v}^{\prime}$ & 0 & Assumed \\
\hline $\begin{array}{l}\text { Proportion cure of MDR-TB with } \\
\text { second'line treatment } \\
\text { (excluding self-cure) }\end{array}$ & $a_{\text {pub2 }}^{\prime}$ & 0.48 & TB India, 2014 [45] \\
\hline $\begin{array}{l}\text { Per-capita mortality hazard } \\
\text { before diagnosis }\end{array}$ & $\mu_{U T B}$ & $0.086(95 \%$ Cl 0.075-0.11) y & See Additional file 1 \\
\hline Mortality hazard during RNTCP treatment & $\mu_{R N T C P}$ & $0.076(95 \% \mathrm{Cl} 0.069-0.095) \mathrm{y}^{-1}$ & See Additional file 1 \\
\hline Mortality hazard during non-RNTCP treatment & $\mu_{\text {non-RNTCP }}$ & $0.27(95 \% \mathrm{Cl} 0.22-0.33) \mathrm{y}^{-1}$ & See Additional file 1 \\
\hline Mortality hazard following default and treatment failure & $\mu_{B}$ & $0.28(95 \% \mathrm{Cl} 0.22-0.36) \mathrm{y}^{-1}$ & See Additional file 1 \\
\hline
\end{tabular}




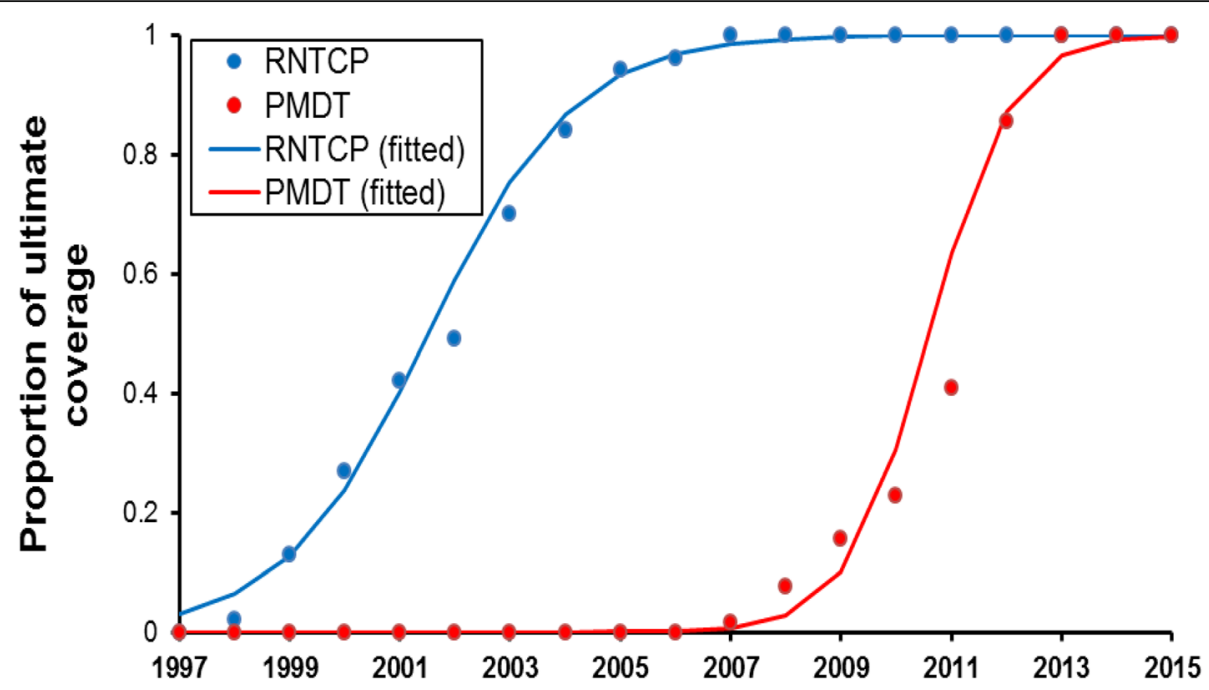

Fig. 2 Scale-up of RNTCP services. Blue points show data for the proportion of geographical coverage of RNTCP [33], while red points show data for the proportion of geographical coverage of PMDT for MDR-TB [33]. As described in the text, these data were used to determine logistic functions capturing the timing and pace ('steepness') of scale-up. Resulting functions are superimposed as blue and red curves, with the following parametric forms: $F(t)=1 /\left[1+\operatorname{Exp}\left(4 \cdot 2-0 \cdot 76^{*} t\right)\right]$ (RNTCP scale-up), $G(t)=1 /\left[1+\operatorname{Exp}\left(20-1 \cdot 37^{*} t\right)\right]$ (PMDT scale-up). Note that a value of 1 on the $y$-axis does not imply that the proportion of TB patients treated by RNTCP is $100 \%$; rather, this proportion is given by $p_{\max } F(t)$, where $p_{\max }$ is a parameter to be estimated (see Methods). That is, $F(t)$ (and similarly $G(t))$ simply represent the proportion of ultimate coverage reached, at a given time during scale-up

RNTCP services from 1997 to 2016, estimating lives saved as the excess deaths between these two scenarios, and assuming no change in the 'non-RNTCP' standard of care over this period. The uncertainty in key model inputs (primarily, per-capita mortality hazards) and calibration targets (incidence, prevalence and percent MDR in 2015) gives rise to uncertainty in estimates for model parameters $\left(\beta, \beta_{\mathrm{MDR}}, r, p_{\max }\right.$ and $\left.q_{\max }\right)$ and thereby in model estimates for lives saved. To drive this 'propagation' of uncertainty from inputs to outputs in a systematic way, we incorporated the error probability distributions described above for mortality hazards, incidence and prevalence, together with uniform priors for the model parameters, in a Bayesian posterior density (see Additional file 1 for further details). We used Bayesian melding [31] to sample from this posterior density to accumulate 250,000 samples for the model parameters. For each sample we then calculated the number of lives saved, to find an ensemble of estimates. From this ensemble we extracted the $2.5^{\text {th }}, 50^{\text {th }}$ and $97.5^{\text {th }}$ percentiles, ultimately to gain point and uncertainty estimates for the lives saved by RNTCP. We refer here to these uncertainty estimates as 'credible intervals' (CrI), to distinguish them from the 'confidence intervals' arising from frequentist statistical approaches.

We also sought to distinguish the TB lives saved directly by improved programmatic conditions from the lives saved as a result of reduced opportunities for transmission: to separate such 'direct' and 'indirect' effects, we sought to estimate direct effects alone, by controlling for transmission. In particular, we calculated the force of infection $\lambda_{R N T C P}(t)$ acting in the simulated, 'RNTCP' scenario. Controlling for transmission effects requires that the same force of infection, as a function of time, should apply even in the absence of RNTCP. Accordingly, we simulated this latter scenario with the force of infection given not as a function of prevalence (as is usually the case), but imposed as the pre-determined $\lambda_{R N T C P}(t)$. We then calculated the lives saved owing to direct effects as the difference in TB mortality between these scenarios. Further details are provided in Additional file 1.

\section{Results}

Table 2 gives the estimates for the model parameters. Epidemic trajectories implied by these estimates are illustrated in Fig. 3, showing projections for incidence and prevalence in the presence and absence of RNTCP. The figure also illustrates the simulation uncertainty in these trajectories arising from the uncertainty in model inputs.

Additional file 1: Figure S1 shows estimates for the annual numbers of TB-related deaths in the presence and absence of RNTCP. The difference between these two scenarios gives the annual lives saved by RNTCP, presented in Fig. 4, together with a separation of direct and indirect effects (see also Table 3 for numbers supporting these plots). Overall, these results suggest that between 1997 and 2016, there were 7.75 million lives (95\% CrI 6.29-8.82 million) saved by RNTCP. Of this impact, 3.28 million lives (95\% CrI 2.58-4.02 million) (roughly $42 \%)$ were attributable to 'indirect' effects of reducing 

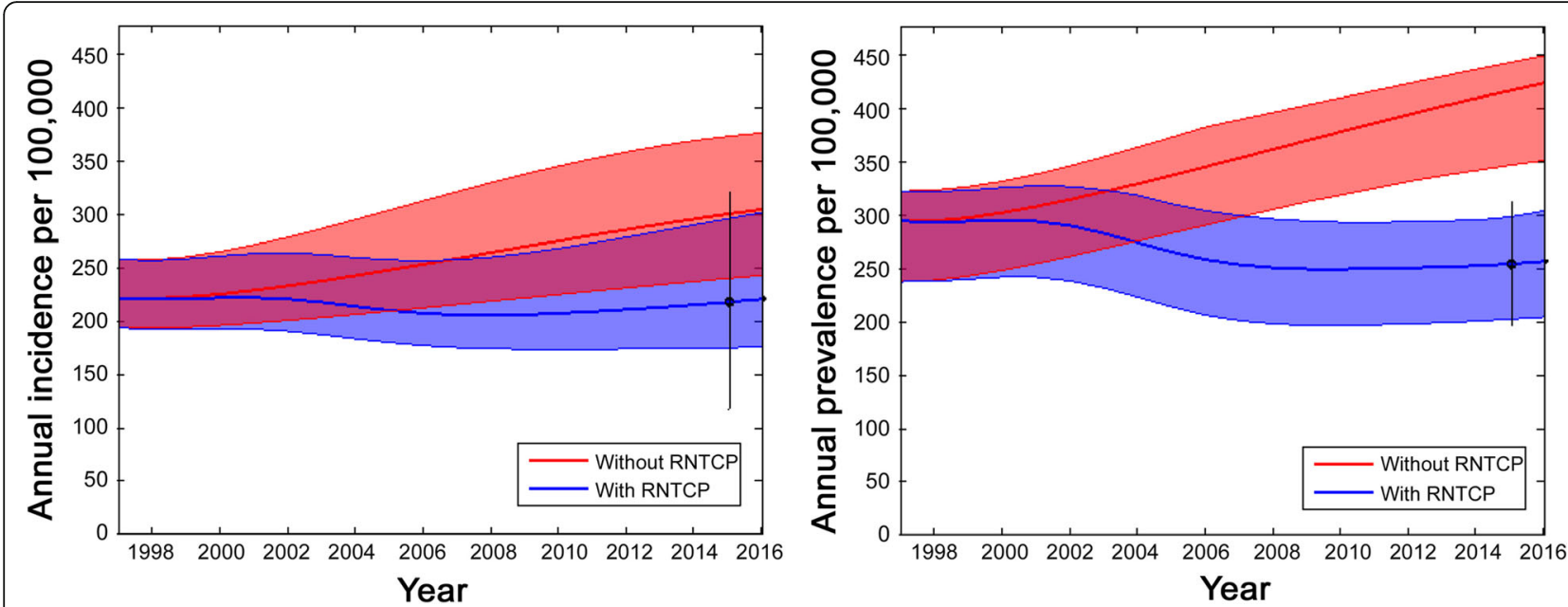

Fig. 3 Model projections for annual TB incidence and prevalence, showing projections in the presence of RNTCP (blue region) and in its absence (red region). To construct these regions, incidence and prevalence curves were determined for each of the parameter sets in the sampled posterior distribution. From the resulting set of curves, upper and lower boundaries for the trajectories were determined using the $2.5^{\text {th }}$ and $97.5^{\text {th }}$ percentiles for incidence and prevalence at each time point. The bold lines represent the epidemic trajectories corresponding to the maximum posterior density (best-fitting parameter set). Circles and uncertainty intervals in black represent WHO estimates for incidence and prevalence

transmission, the remainder attributable to the direct programmatic effects that would have arisen in the absence of any transmission impact. Additional results (Additional file 1: Table S3) suggest that a total of 42.48 million TB patients (95\% CrI 33.94-47.91 million) were cured through TB treatment over the same period.

Additional file 1: Table S3 additionally separates lives saved by drug susceptibility status, suggesting that
RNTCP and PMDT together averted 1.50 million MDRTB deaths (95\% CrI 1.22-1.74 million) from 1997-2016. However, not all of this impact was due to PMDT: because of the effects of RNTCP in reducing transmission even before the initiation of PMDT in 2007, there were fewer patients on first-line treatment than might otherwise have occurred, and thus fewer opportunities for the acquisition of drug resistance during treatment. Overall

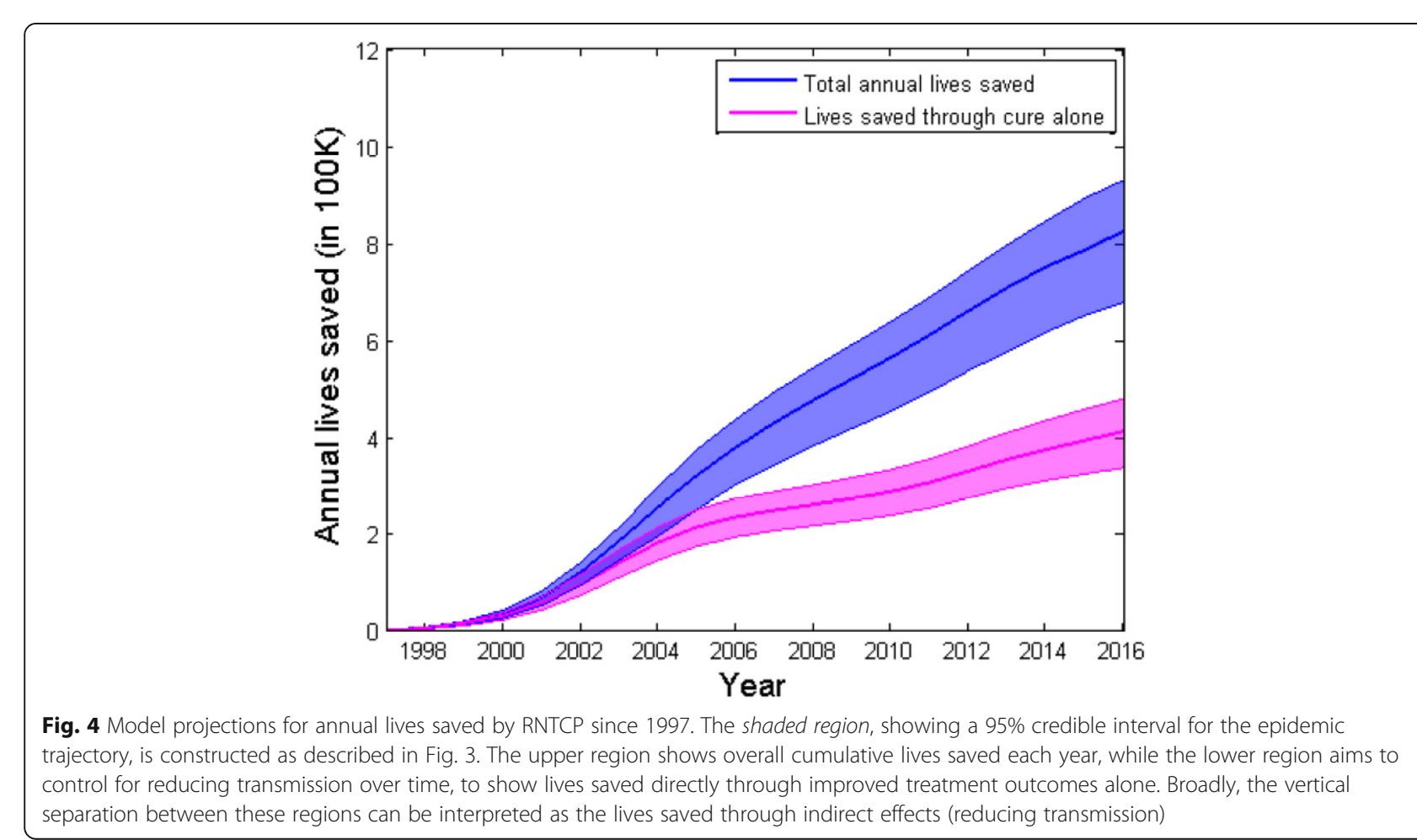


Table 3 Estimated deaths averted by RNTCP from 1997-2016 Crl credible interval

\begin{tabular}{llll}
\hline & Direct effects & Indirect effects & Total lives saved \\
\hline DS-TB lives saved & $\begin{array}{l}3.53 \text { million (95\% Crl* 2.86-4.11 } \\
\text { million) }\end{array}$ & $\begin{array}{l}2.57 \text { million lives (95\% Crl 1.80-3.09 } \\
\text { million) }\end{array}$ & $\begin{array}{l}6.25 \text { million lives (95\% Crl 4.96-7.14 } \\
\text { million) }\end{array}$ \\
MDR-TB lives saved & $\begin{array}{l}0.71 \text { million (95\% Crl 0.61-0.79 } \\
\text { million) }\end{array}$ & $\begin{array}{l}0.76 \text { million (95\% Crl 0.60-0.96 } \\
\text { million) }\end{array}$ & $\begin{array}{l}1.50 \text { million lives (95\% Crl 1.22-1.74 } \\
\text { million) }\end{array}$ \\
Total lives saved & $\begin{array}{l}4.23 \text { million lives (95\% Crl 3.52-4.89 } \\
\text { million) }\end{array}$ & $\begin{array}{l}3.28 \text { million lives (95\% Crl 2.58-4.02 } \\
\text { million) }\end{array}$ & $\begin{array}{l}7.75 \text { million lives (95\% Crl 6.29-8.82 } \\
\text { million) }\end{array}$ \\
\hline
\end{tabular}

$(*)$ : As described in the main text, $\mathrm{Crl}$ denotes 'credible intervals'.

this amounts to a substantial indirect effect in averting cases of MDR-TB.

\section{Discussion}

Nationally coordinated, high-quality TB services, as embodied by the DOTS strategy, are key in improving outcomes for patients with TB [32]. A difficult but important task is to project from this patient-level perspective to understand population-level impact. Here we have applied a mathematical model of TB transmission to address this need, in the context of the world's largest national TB programme using DOTS. Our results suggest that, from 1997 to2016, India's RNTCP has saved 7.75 million lives with roughly $42 \%$ of this impact arising from preventive, rather than curative, benefits.

As noted earlier, previous work estimated that RNTCP averted 1.26 million TB deaths from 1997 to 2006 [17]. By comparison, our work suggests a higher total impact of 1.41 million lives (95\% CrI 1.08-1.62 million) saved over this period (note that Table 3 shows lives saved from 1997 to 2016). A major reason for this difference is that previous studies did not take into consideration the indirect effects due to reduced transmission and the lives saved from MDR-TB. Moreover, we have developed a model considering several parameters that govern the disease dynamics in individuals and in the community, while earlier estimations were based solely on the difference in case fatality rates under RNTCP and non-RNTCP conditions. As another comparison, our model suggests that in 2015, TB mortality in India amounted to 58 (38-75) deaths per 100,000 population. This is roughly comparable with, although somewhat higher than, independent WHO estimates of 36 (29-45) TB deaths per 100,000 population, in 2015 [1].

While a full cost-effectiveness analysis is beyond the scope of this study, we consider drug-susceptible (DS)-TB as a rough indication (separating MDR-TB, as its disproportionate costs would otherwise obscure the cost-impact ratio amongst DS cases). With an overall expenditure of USD 2710 million from 1997-2015 excluding PMDT (see Additional file 1: Table S4) [33, 34], and an estimated 5.64 million lives saved from TB over this time, our results suggest that it has cost USD 480 per DS-TB death averted.

However, TB in India has much ground still to cover. In particular, much of TB treatment happens not under the
RNCTP, but in a vast and unregulated private healthcare sector, with evidence of substandard care $[18,21,35,36]$. Correspondingly, our results suggest that - while TB incidence in India has indeed been reduced over time - it has nonetheless settled at a new plateau (Fig. 3). In practice, this plateau reflects the limit of what could be achieved through the current public sector alone. Engagement with the private healthcare sector, as well as addressing inefficiencies in the public health system itself, will be key in addressing this substantial remainder of India's TB burden [35, 37].

Our work could also be applied to other national contexts. For example, Indonesia and other high-burden countries in the region also face challenges of a lack of reliable vital registration data [38]. China has completed several national prevalence surveys, offering evidence for actual epidemiological trends through time in that country [39]. On the other hand, for settings such as those in South Africa [40], it is not possible to neglect HIV/TB coinfection as we have done in the present work: a more developed model will be a valuable extension for future work.

As with any modelling study, there are limitations to note. In the absence of adequate data we have neglected secular trends that may have affected TB transmission over the last two decades, such as growing urbanization; an increasing prevalence of comorbidities, including diabetes; and changes in socioeconomic and living conditions. We have also used WHO incidence estimates, themselves derived from certain assumptions. Nonetheless, our findings should be seen as a demonstration of principle that could be refined with improved TB burden estimates from India. More robust data on the trends of TB burden over time (for example, through a series of prevalence surveys) could help to refine the model estimates. Moreover, in modelling the TB epidemic at country level, we have neglected subnational differences such as urban vs rural TB, as well as the unique burden of MDR-TB in locations such as Mumbai. Further work could aim to extend this analysis to these settings.

We have also made several model simplifications, for example, assuming a fixed delay before initiating treatment (even if this delay is estimated). If RNTCP scale-up meant that patients were diagnosed earlier, or indeed that $\mathrm{TB}$ patients would more readily seek care at newly available facilities, this would have reduced delays to diagnosis. An assumption of constant $r$ would thus be conservative with 
respect to RNTCP impact. In modelling the absence of the RNTCP under the counterfactual scenario, we have also assumed that the standard of TB care in non-RNTCP services has remained roughly constant over time [20, 25]. Nonetheless, if non-RNTCP practices have in fact improved in India, this may reduce the overall lives saved by RNTCP. For simplicity we have also assumed that there is no difference in long-term outcomes between patients completing RNTCP and non-RNCTP treatment. With no adherence support in the private sector, however, patients stopping treatment early may face increased risks of relapse [41], with attendant risks of TB mortality. Once again, ignoring this would tend to be conservative with respect to RNTCP impact. We have also neglected age structure and the differential mortality that is likely to apply amongst pediatric cases of TB [42], given the particular challenges in diagnosing these cases. Another limitation is that we have not segregated the lives saved amongst smear-positive and smear-negative cases. Given the differential case fatality rates as observed amongst untreated smear-positive and smear-negative cases and that more emphasis has been given to smear-positive case detection (cases having a higher mortality hazard [26]), lives saved are likely to be underestimates. Finally, in the absence of reliable vital registration data, we have had to construct mortality estimates from the available literature. Ideally these estimates could be validated against in-country mortality data; while these data are currently not sufficiently robust [12], future TB mortality studies - both nationally and on the subnational level - would be invaluable in informing and refining these estimates.

\section{Conclusions}

While there remains much ground to be covered in managing India's TB epidemic, it is also valuable to note that the RNTCP has had a substantial impact over the past two decades. In the present work, we show that over $40 \%$ of the overall impact of DOTS in India could be attributed to reduced transmission. Complex though this impact may be, mathematical modelling can offer a helpful tool for understanding these effects, both in India and for TB control programmes elsewhere.

\section{Additional file}

Additional file 1: Model specification and additional technical details. (DOCX $165 \mathrm{~kb}$ )

\section{Abbreviations}

DOTS: Directly Observed Treatment Short Course; MDR-TB: Multi-drugresistant tuberculosis; PMDT: Programmatic Management of Drug-Resistant Tuberculosis; RNTCP: Revised National Tuberculosis Control Programme; TB: Tuberculosis; WHO: World Health Organization

\section{Funding}

This work was supported by the Bill and Melinda Gates Foundation (BMGF). The funder had no role in study design, interpretation of results or publication decisions. The corresponding author had full access to all data and final responsibility for publication decisions.

\section{Availability of data and materials}

All data generated or analysed during this study are included in this published article and its additional file.

\section{Authors' contributions}

VC and NA conceived the study; SM developed the model and performed the analysis; SM, VC, RL and NA all contributed to the interpretation of the results; SM and NA wrote a first draft of the manuscript; all authors contributed in developing the final draft. All authors read and approved the final manuscript.

\section{Competing interests}

The authors declare that they have no competing interests.

\section{Consent for publication}

Not applicable.

Ethics approval and consent to participate

Not applicable.

\section{Author details}

${ }^{1}$ Public Health Foundation of India, New Delhi, India. ${ }^{2}$ Epidemiology and Research Division, National Tuberculosis Institute, Bangalore, India. ${ }^{3}$ Center for Disease Dynamics, Economics, and Policy, Washington, DC, USA. ${ }^{4}$ Princeton University, Princeton, NJ, USA. ${ }^{5}$ Department of Infectious Disease Epidemiology, Faculty of Medicine, Imperial College, London, UK.

Received: 18 October 2016 Accepted: 6 February 2017

Published online: 03 March 2017

\section{References}

1. World Health Organization. Global tuberculosis report 2016. World Health Organization 2016. WHO Press, Geneva. WHO/HTM/TB/2016.13.

2. Raviglione $\mathrm{MC}$, Pio A. Evolution of $\mathrm{WHO}$ policies for tuberculosis control, 1948-2001. Lancet. 2002;359(9308):775-80.

3. World Health Organization.A brief history of tuberculosis control in India. 2010. http://apps.who.int/iris/bitstream/10665/44408/1/9789241500159_eng. pdf. Accessed 02 Jan 2017.

4. World Health Organization. Millennium Development Goals (MDGs) MDG 6: combat HIV/AIDS, malaria and other diseases. 2014. http://www.who.int topics/millennium_development_goals/diseases/en/. Accessed 13 Sept 2016.

5. Atun $R$, Raviglione M, Marais $B$, Zumla A. Tuberculosis control is crucial to achieve the MDGs. Lancet. 2010;376(9745):940-1.

6. The stop TB strategy. (2006). http://apps.who.int/iris/bitstream/10665/69241/ 1/WHO_HTM_STB_2006.368_eng.pdf. Accessed 2 Jan 2017.

7. End WHO, Strategy TB. Global strategy and targets for tuberculosis prevention, care and control after 2015. 2015. http://www.who.int/tb/ strategy/en/. Accessed 13 Sept 2016.

8. The Global Fund results report. 2015. http://www.theglobalfund.org/en/ downloads/. Accessed 13 Sept 2016.

9. Glaziou P, Floyd K, Korenromp EL, et al. Lives saved by tuberculosis control and prospects for achieving the 2015 global target for reducing tuberculosis mortality. Bull World Health Organ. 2011;89:573-82. doi:10. 2471/BLT.11.087510.

10. McCoy D, Jensen N, Kranzer K, Ferrand RA, Korenromp EL. Methodological and policy limitations of quantifying the saving of lives: a case study of the global fund's approach. PLoS Med. 2013;10(10):e1001522. doi:10.1371/ journal.pmed.1001522.

11. Dye C, Williams BG. The population dynamics and control of tuberculosis. Science. 2010:328(5980):856-61. doi:10.1126/science.1185449.

12. Cowling K, Dandona R, Dandona L. Improving the estimation of the tuberculosis burden in India. Bull World Health Organ. 2014;92:817-25.

13. Jha P, Gajalakshmi V, Gupta PC, et al. Prospective study of one million deaths in India: rationale, design, and validation results. Avila MH, ed. PLoS Med. 2006;3(2):e18. doi:10.1371/journal.pmed.0030018. 
14. World Health Organization. Health situation and trend assessment. http:// www.searo.who.int/entity/health_situation_trends/data/chi/vital-registration/ en/. Accessed 02 Jan 2017

15. Menzies NA, Cohen T, Lin H-H, Murray M, Salomon JA. Population health impact and cost-effectiveness of tuberculosis diagnosis with Xpert MTB/RIF: a dynamic simulation and economic evaluation. PLoS Med. 2012:9(11): e1001347. doi:10.1371/journal.pmed.1001347.

16. Sachdeva KS, Raizada N, Gupta RS, et al. The potential impact of up-front drug sensitivity testing on India's epidemic of multi-drug resistant tuberculosis. PLoS One. 2015;10(7):e0131438. doi:10.1371/journal.pone.0131438.

17. Goodchild M, Sahu S, Wares F, et al. A cost-benefit analysis of scaling up tuberculosis control in India. Int J Tuberc Lung Dis. 2011;15(3):358-62.

18. Satyanarayana S, Nair SA, Chadha SS, et al. From where are tuberculosis patients accessing treatment in India? Results from a cross-sectional community based survey of 30 districts. PLoS One. 2011;6(9):e24160. doi:10. 1371/journal.pone.0024160

19. Sreeramareddy CT, Qin ZZ, Satyanarayana S, Subbaraman R, Pai M. Delays in diagnosis and treatment of pulmonary tuberculosis in India: a systematic review. Int J Tuberc Lung Dis. 2014;18(3):255-66. doi:10.5588/ijtld.13.0585.

20. Udwadia ZF, Pinto LM, Uplekar MW. Tuberculosis management by private practitioners in Mumbai, India: has anything changed in two decades? PLoS One. 2010;5(8):e12023. doi:10.1371/journal.pone.0012023.

21. Das J, Kwan A, Daniels B, et al. Use of standardised patients to assess quality of tuberculosis care: a pilot, cross-sectional study. Lancet Infect Dis. 2015;15(11):1305-13.

22. Arinaminpathy $N$, Batra D, Khaparde $S$, et al. The number of privately treated tuberculosis cases in India: an estimation from drug sales data. Lancet Infect Dis. 2016;16(11):1255-60. doi:10.1016/S1473-3099(16)30259-6.

23. Balasubramanian VN, Oommen K, Samuel R. DOT or not? Direct observation of anti-tuberculosis treatment and patient outcomes, Kerala State. India Int J Tuberc Lung Dis. 2000:4(5):409-13.

24. Datta M, Radhamani MP, Selvaraj R, et al. Critical assessment of smearpositive pulmonary tuberculosis patients after chemotherapy under the district tuberculosis programme. Tuber Lung Dis. 1993;74(3):180-6.

25. Uplekar MW, Shepard DS. Treatment of tuberculosis by private genera practitioners in India. Tubercle. 1991;72(4):284-90.

26. Tiemersma EW, van der Werf MJ, Borgdorff MW, Williams BG, Nagelkerke NJD. Natural history of tuberculosis: duration and fatality of untreated pulmonary tuberculosis in HIV negative patients: a systematic review. PLoS One. 2011;6(4):e17601. doi:10.1371/journal.pone.0017601.

27. Pandey S, Chadha V, Laxminarayan R, Arinaminpathy N. Estimating tuberculosis incidence from primary survey data: a mathematical modelling approach. Int J Tuberc Lung Dis. In press.

28. Chadha VK, Sarin R, Narang P, John KR, et al. Trends in the annual risk of tuberculosis infection in India. In J Tuberc Lung Dis. 2013;17(3):312-9.

29. Uplekar M, Juvekar S, Morankar S, Rangan S, Nunn P. Tuberculosis patients and practitioners in private clinics in India. Int J Tuberc Lung Dis. 1998;2(4):324-9.

30. Vijay S, Balasangameswara VH, Jagannatha PS, Saroja VN, Kumar P. Treatment outcome and two \& half years' follow-up status of new smear positive patients treated under RNCTP. Indian J Tuberc. 2004;51:199-208.

31. Poole D, Raftery AE. Inference for deterministic simulation models: The Bayesian melding approach. J Am Statist Ass. 2000;95(452):1244-55.

32. Small P. Why India should become a global leader in high-quality, affordable TB diagnostics. Indian J Med Res. 2012;135(5):685-9.

33. Central TB Division, Directorate General Health Services, Ministry of Health and Family Welfare, Government of India - Revised National TB Control Programme. TB India. 2013. http://www.tbcindia.nic.in. Accessed 30 Aug 2016.

34. Central TB Division, Directorate General Health Services, Ministry of Health and Family Welfare, Government of India - Revised National TB Control Programme. TB India. 2015. http://www.tbcindia.nic.in. Accessed 30 August 2016.

35. Wells WA, Uplekar M, Pai M. Achieving systemic and scalable private sector engagement in tuberculosis care and prevention in Asia. PLoS Med. 2015; 12(6):e1001842. doi:10.1371/journal.pmed.1001842.

36. Kapoor SK, Raman AV, Sachdeva KS, Satyanarayana S. How did the TB patients reach DOTS services in Delhi? A study of patient treatment seeking behavior. PLoS One. 2012;7(8):e42458. doi:10.1371/journal.pone.0042458.

37. Pai M, Dewan P. Testing and treating the missing millions with tuberculosis. PLoS Med. 2015;12(3):e1001805. doi:10.1371/journal.pmed.1001805.

38. Basu S, Andrews J, Kishore S, Panjabi R, Stuckler D. Comparative performance of private and public healthcare systems in low- and middle income countries: a systematic review. PLoS Med. 2012;9(6):e1001244. doi: 10.1371/journal.pmed.1001244.
39. Wang L, Zhang H, Ruan Y, et al. Tuberculosis prevalence in China, 1990-2010; a longitudinal analysis of national survey data. Lancet. 2014;383(9934):2057-64.

40. Abdool Karim SS, Churchyard GJ, Abdool Karim Q, Lawn SD. HIV infection and tuberculosis in South Africa: an urgent need to escalate the public health response. Lancet. 2009;374(9693):921-33. doi:10.1016/S01406736(09)60916-8.

41. Menzies D, Benedetti A, Paydar A, et al. Effect of duration and intermittency of rifampin on tuberculosis treatment outcomes: a systematic review and metaanalysis. PLoS Med. 2009;6(9):e1000146. doi:10.1371/journal.pmed.1000146.

42. Vynnycky E, Fine PE. The natural history of tuberculosis: the implications of age-dependent risks of disease and the role of reinfection. Epidemiol Infect. 1997;119:183-201.

43. Horsburgh CR, O'Donnell M, Chamblee $\mathrm{S}$, et al. Revisiting rates of reactivation tuberculosis: a population-based approach. Am J Respir Crit Care Med. 2010;182(3):420-5. doi:10.1164/rccm.200909-13550C.

44. Sun AY, Pai M, Salje H, Satyanarayana S, Deo S, Dowdy DW. Modeling the impact of alternative strategies for rapid molecular diagnosis of tuberculosis in Southeast Asia. Am J Epidemiol. 2013;178(12):1740-9.

45. Central TB Division, Directorate General Health Services, Ministry of Health and Family Welfare, Government of India - Revised National TB Control Programme. TB India. 2014. http://www.tbcindia.nic.in. Accessed 30 Aug 2016.

\section{Submit your next manuscript to BioMed Central and we will help you at every step:}

- We accept pre-submission inquiries

- Our selector tool helps you to find the most relevant journal

- We provide round the clock customer support

- Convenient online submission

- Thorough peer review

- Inclusion in PubMed and all major indexing services

- Maximum visibility for your research

Submit your manuscript at www biomedcentral.com/submit
C Biomed Central 